\title{
Effect of bone material properties on effective region in screw-bone model: an experimental and finite element study
}

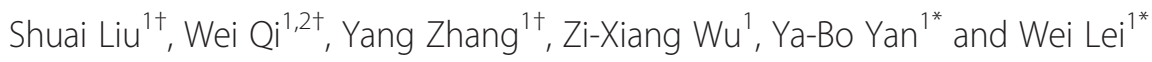

\begin{tabular}{l}
\hline *Correspondence: \\
yanyabo@gmail.com; \\
leiwei@fmmu.edu.cn \\
${ }^{\dagger}$ Equal contributors \\
${ }^{1}$ Department of Orthopaedics, \\
Xijing Hospital, Fourth Military \\
Medical University, Xi'an 710032, \\
Shaanxi Province, P.R. China \\
Full list of author information is \\
available at the end of the article
\end{tabular}

* Correspondence: yanyabo@gmail.com

Xijing Hospital, Fourth Military

Medical University, Xi'an 710032

Full list of author information is

avallable at the end of the article

\begin{abstract}
Background: There have been numerous studies conducted to investigate the pullout force of pedicle screws in bone with different material properties. However, fewer studies have investigated the region of effect (RoE), stress distribution and contour pattern of the cancellous bone surrounding the pedicle screw.
\end{abstract}

Methods: Screw pullout experiments were performed from two different foams and the corresponding reaction force was documented for the validation of a computational pedicle screw-foam model based on finite element (FE) methods. After validation, pullout simulations were performed on screw-bone models, with different bone material properties to model three different age groups $(<50,50-75$ and $>75$ years old). At maximum pullout force, the stress distribution and average magnitude of Von Mises stress were documented in the cancellous bone along the distance beyond the outer perimeter pedicle screw. The radius and volume of the RoE were predicted based on the stress distribution.

Results: The screw pullout strengths and the load-displacement curves were comparable between the numerical simulation and experimental tests. The stress distribution of the simulated screw-bone vertebral unit showed that the radius and volume of the RoE varied with the bone material properties. The radii were $4.73 \mathrm{~mm}, 5.06 \mathrm{~mm}$ and $5.4 \mathrm{~mm}$ for bone properties of ages $>75,75>$ ages $>50$ and ages $<50$ years old, respectively, and the corresponding volumes of the RoE were $6.67 \mathrm{~mm}^{3}, 7.35 \mathrm{~mm}^{3}$ and $8.07 \mathrm{~mm}^{3}$, respectively.

Conclusions: This study demonstrated that there existed a circular effective region surrounding the pedicle screw for stabilization and that this region was sensitive to the bone material characteristics of cancellous bone. The proper amount of injection cement for augmentation could be estimated based on the RoE in the treatment of osteoporosis patients to avoid leakage in spine surgery.

Keywords: Biomechanics, Pedicle screw, Cancellous bone, Finite element analysis

\section{Background}

Osteoporosis is a common skeletal disorder of the spine and hip in the elderly population. Spine surgeons often encounter patients with osteoporotic spines that require spinal decompression and management with surgical instrumentation due to degenerative and traumatic spinal diseases [1,2]. Pedicle screw fixation is a routine tool for spine stabilization, with the screw providing rigid bony secured points on internal

(c) 2014 Liu et al.; licensee BioMed Central Ltd. This is an Open Access article distributed under the terms of the Creative Commons Attribution License (http://creativecommons.org/licenses/by/4.0), which permits unrestricted use, distribution, and reproduction in any medium, provided the original work is properly credited. The Creative Commons Public Domain Dedication waiver (http:// creativecommons.org/publicdomain/zero/1.0/) applies to the data made available in this article, unless otherwise stated. 
fixation devices. However, it is a challenge for spine surgeons to perform pedicle screw instrumentation surgery on osteoporotic spines to prevent many potential complications, such as screw loosening, migration or back-out [3]. It has been reported that the mechanical strength of the bone-screw interface is adversely affected by low bone density in patients with osteoporosis $[4,5]$.

Different methods have been used to enhance the short- and long-term stability of implanted screws in the osteoporotic lumbar spine [6,7]. The in situ injection of biomaterials, such as calcium phosphate cement (CPC), calcium sulfate cement (CSC), and polymethyl-methacrylate (PMMA), into the screw hole is a common option for enhancing pedicle screw fixation strength $[8,9]$. Although pedicle screw augmentation with cement is an attractive option for improving screw fixation, there exist risks of excessive cement leakage beyond the confined target bone, affecting the spinal cord and resulting in nerve compression [10]. A smaller-volume cement injection might not enhance the augmentation screw performance.

Although there have been many experimental screw-bone interaction studies, it is technically difficult to determine the region of effect (RoE) by observing the screwbone interaction during pullout testing. Sources in the literature have reported that the pullout strength of the pedicle screw increased from $147 \%$ to $300 \%$ [9-12] when the amount of cement injection varied from approximately 1 to $3.5 \mathrm{ml}$. Liu et al. [7] and Chang et al. [9] demonstrated that an appropriate volume of injection could be obtained by investigating of the interaction between the pedicle screw and cancellous bone. Compared to experimental models, finite element (FE) models provide the opportunity to document related mechanical responses during simulation [13]. Some researchers have used FE models for screw-bone interaction studies. Moazen $\mathrm{M}$ et al. [14] evaluated the screw-bone interface model in a locking plate fixation through a corroboration study. Zhang et al. [15] developed a quarter screw-bone model and studied the effects of the bone material on the screw pullout strength. Chatzistergos et al. [16] used a two-dimensional screw-bone model to perform a parametric study of pedicle screw design. Because the pullout force is set as the dominant index for the evaluation of screw fixation, there have been numerous studies conducted regarding in this aspect, with fewer researchers investigating RoE, stress distribution and the contour pattern of the cancellous bone surrounding the pedicle screw.

Based on the pullout experiments $[6,7,17]$ and micro-structural studies of the vertebral cancellous bone $[18,19]$, we speculated that there existed an effective region or an enclosed RoE around the perimeter of the pedicle screw that might play a pivotal role in the stabilization of the pedicle screw during screw pullout. Therefore, the purpose of this study was to investigate the existence of a region of effect in the pedicle screw pullout procedure and the sensitivity of this region to the material properties of the cancellous bone. Accordingly, an experimentally validated three-dimensional FE model of a screwbone unit was established and used to determine the RoE in screw pullout simulations.

\section{Methods}

\section{Experimental study}

Sixteen conventional pedicle screws (CDH Ø $6.5 \times 40 \mathrm{~mm}$ ) and polyurethane foam (an alternative test medium, analogous to human cancellous bone, with uniform and 
consistent mechanical properties (according to ASTM F-1839)) were used. Two different types of polyurethane foam with different properties $-\rho=0.16 \mathrm{~g} / \mathrm{cc}$, porous cell size 0.5 to $2.0 \mathrm{~mm}$, and Young's modulus of $23 \mathrm{MPa}$; and $\rho=0.32 \mathrm{~g} / \mathrm{cc}$, porous cell size 0.5 to $1.0 \mathrm{~mm}$, and Young's modulus of $137.5 \mathrm{MPa}$, [20,21], which approximated to human osteoporotic cancellous bone characteristics and normal cancellous bone characteristics, respectively, were utilized (Figure 1). In accordance to the ASTM-F543 standard testing procedure, the pullout force was obtained of the pedicle screws from these two different densities of solid rigid polyurethane foam blocks (10 pfc, Sawbones Worldwide, Pacific Research Laboratories Inc).

The screw-foam samples were prepared according to the surgical procedure. First, guiding holes with diameters of $3.5 \mathrm{~mm}$ and depths of $50 \mathrm{~mm}$ were drilled into the polyurethane blocks, and these guiding holes were then tapped manually, using the taps provided by the manufacturer (CD Horizon legacy MD-8 system, Medtronic Sofamor Danek Inc., Memphis, TN, USA). Finally, the $6.5 \times 40-\mathrm{mm}$ pedicle screws with 13 threads were screwed into the the polyurethane block to the full dept. The guiding holes were $10 \mathrm{~mm}$ deeper than the desired screw insertion depth, to ensure that the tip of the screw was not pressed against the bottom of the guiding hole, thus avoiding the

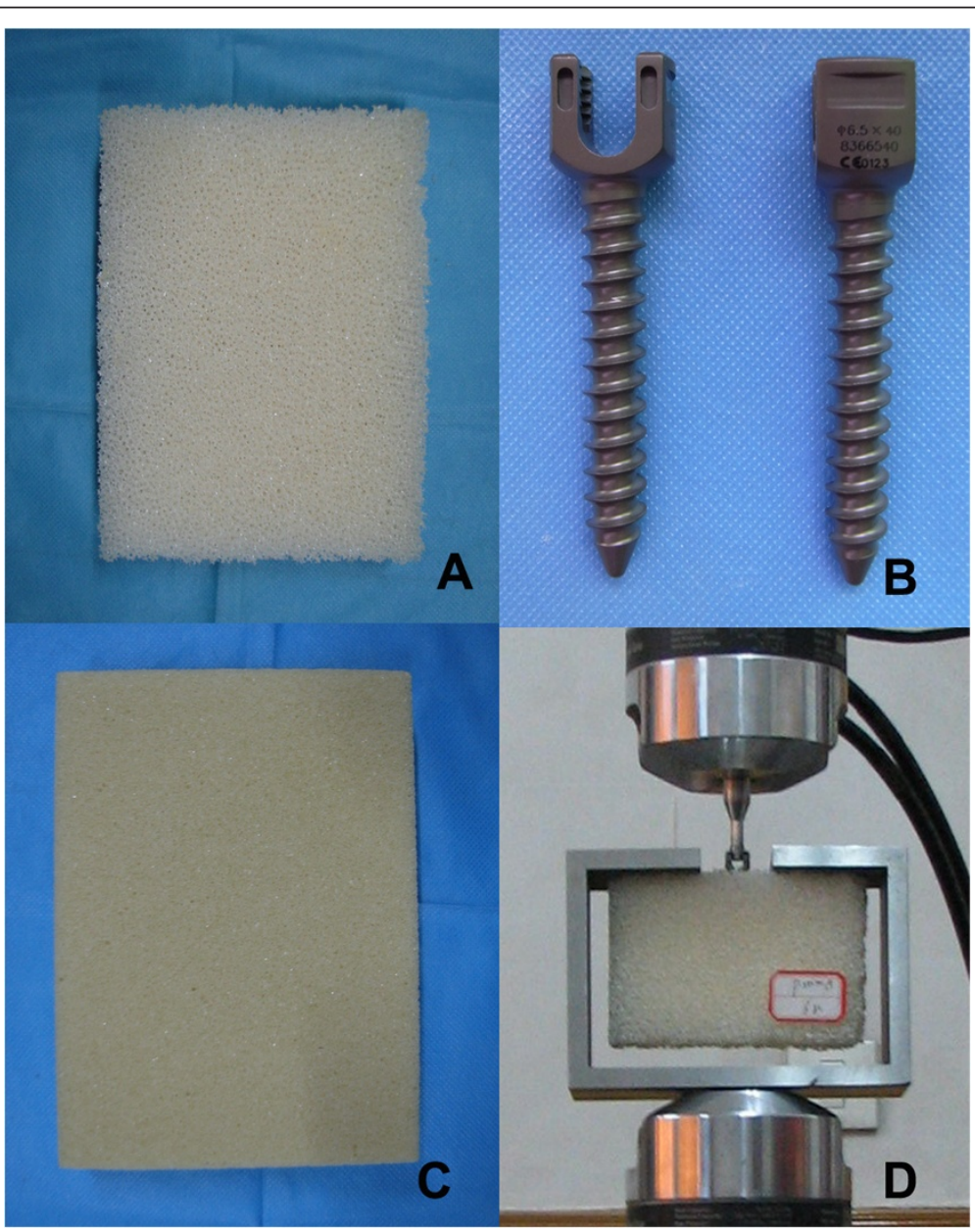

Figure 1 The pullout experimental setup configuration. A: Foam with lower density; B: $\mathrm{CDH} \varnothing 6.5 \times 40 \mathrm{~mm}$ pedicle screw; C: Foam with higher density; D: Pullout test configuration. 
generation of undesired pretension on the foams block [22]. Sixteen pedicle screws were randomly divided into two groups and were screwed into the polyurethane blocks.

Figure 2 shows the pullout experimental setup configuration. The pullout test jig consisted of an open C-channel rigid frame secured to the base of loading frame and a special fabricated rod, with one end threaded to screw into the head of the pedicle screw of the block sample and its enlarged end rigidly clamped to the upper moving cross head of the loading frame (MTS MiniBionix 858, MTS systems Corp, Eden Prairie, MN, USA). The upper moving cross-head was controlled to displace in the pull-out direction at a constant rate of $0.01 \mathrm{~mm} / \mathrm{s}$ [22], and the corresponding reaction force was documented at a sampling rate of $10 \mathrm{~Hz}$. Load-displacement graphs were plotted for all the samples, and the average maximum pullout force was computed for the two different screw-foam samples.

\section{FE model design}

Because the screw-bone interface was periodically symmetric, and a linear correlation existed between the number of threads and pullout strength $[15,16]$, a quarter unit model with only one thread was established for computational efficiency. Three FE models were developed: two screw-foam models were used for the validation study, and one screw-bone model was used for the material sensitivity analysis. Using Pro/Engineer software (PTC, Needham, MA, USA), based on the dimensions and profiles of the screw thread specifications of the standard pedicle screws $[16,23]$, the correct geometries of the pedicle screws were created. Separately, a quarter cylindrical block, $18 \mathrm{~mm}$ in diameter and $4 \mathrm{~mm}$ in length, was created. A threaded hole that matched the pedicle screw profile was created at the center of the block. The created three-dimensional

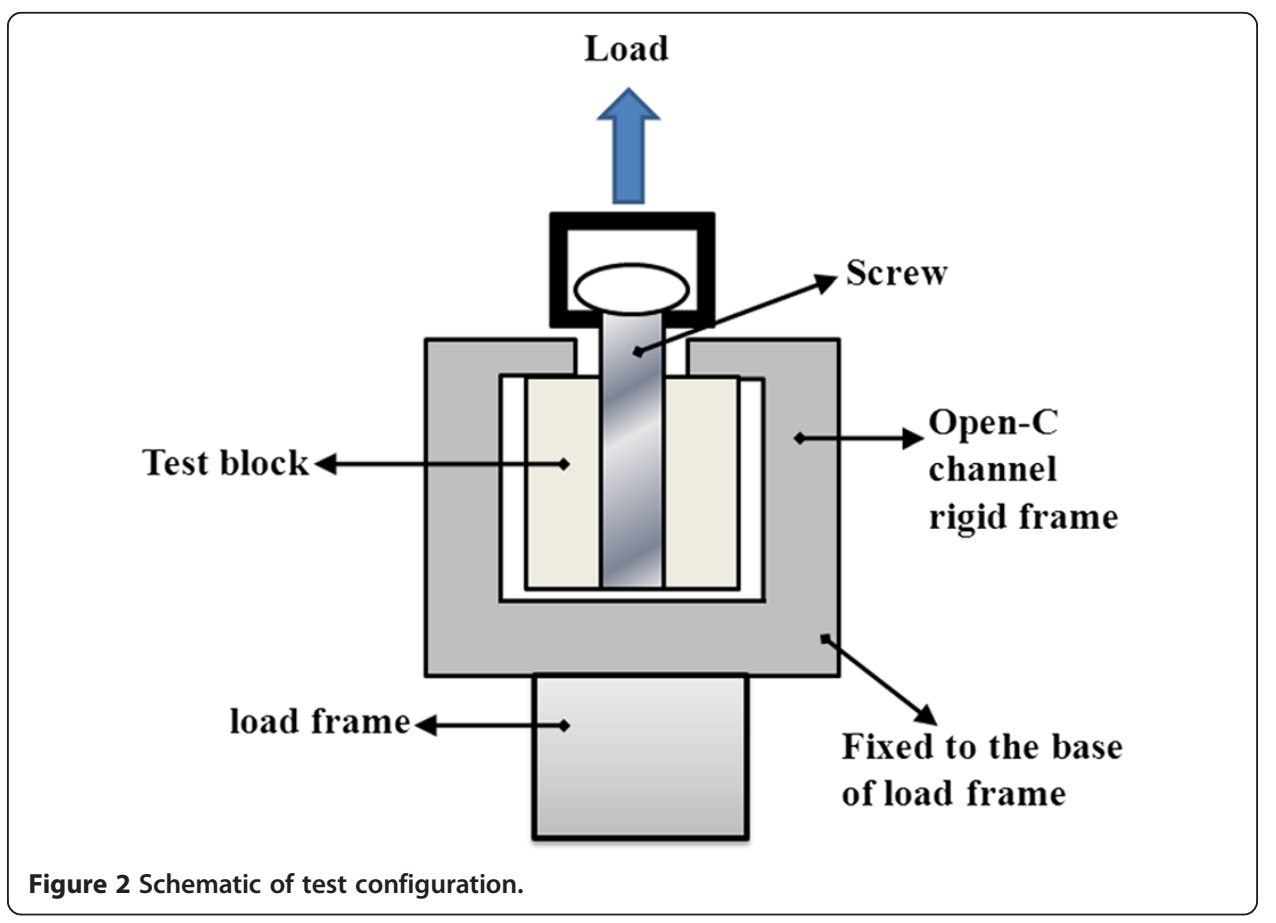


geometries were then imported into ANSYS/LS-Dyna (ANSYS Inc., Canonsburg, PA, USA) for FE mesh generation.

For a reasonable representation of the actual matching geometry between the foam/ bone and screw threads, a fine mesh $(0.1 \mathrm{~mm}$ in average length) was adopted, while a relatively coarser mesh $(0.3 \mathrm{~mm}$ in average length) was adopted for the other regions. For the region between the interfaced threads, significant mesh refinement was used to obtain better stress distribution around the cancellous bone tissue in this area [24,25]. The FE meshed screw and block models were assembled to generate the final FE screw-foam/ bone model. In this study, an eight-noded isoparameteric brick solid element was chosen. Convergence testing was performed, and the final FE model consisting of 99,354 elements and 36,506 nodes (Figure 3), was subsequently used for further simulation study.

To simulate the contacts between the foam/bone and screws at their interfaces under pullout loading conditions, the surface-to-surface contact relationship was employed in the model. Contact pairs were defined between the foam/bone and screws, with the trailing edge of the screw chosen as the master surface and those elements of the foam/bone chosen as the slave surface.

The material properties of the foams adopted from the literature [22], which were used for the FE screw-foam model, are shown in Table 1.

\section{FE model validation}

The validation of the FE screw-foam model was conducted by evaluating the predicted screw pullout strengths and the pullout force-displacement curves against the

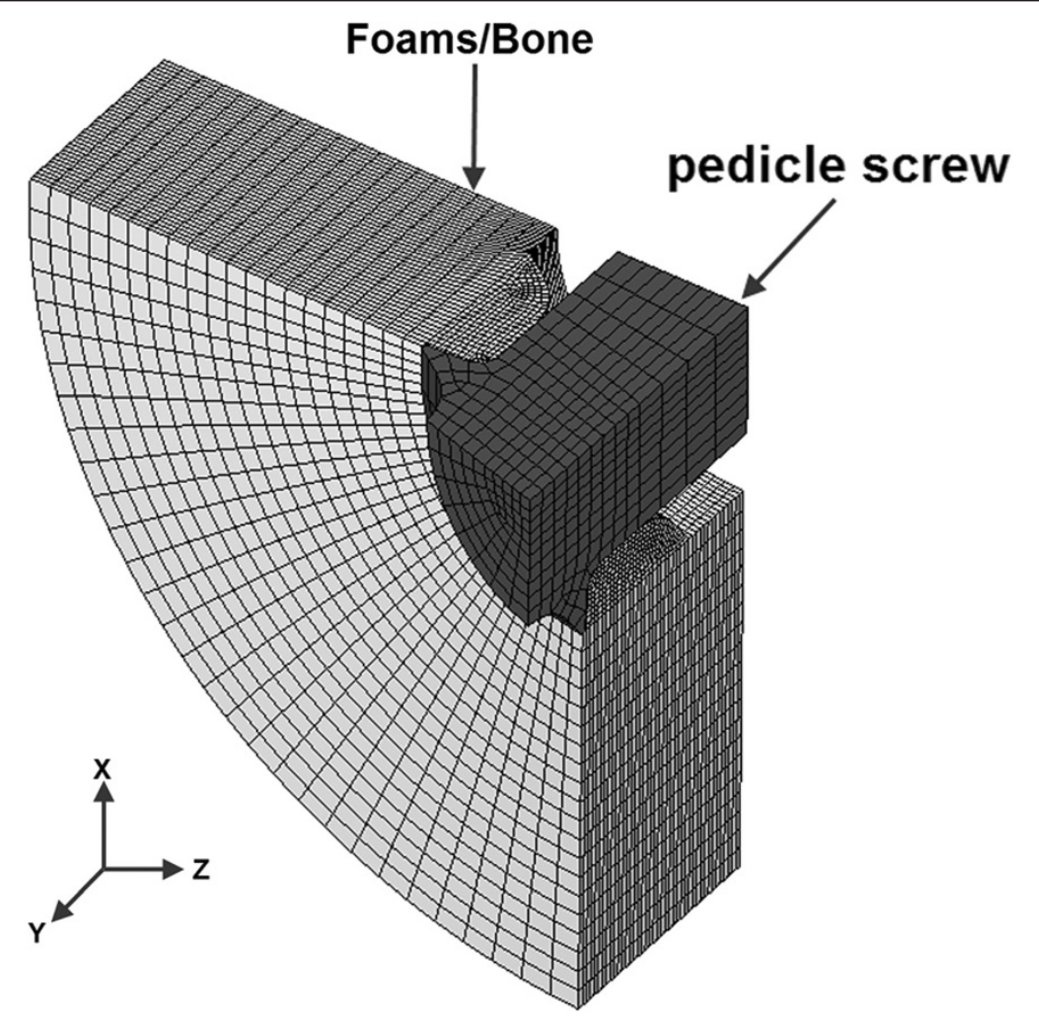

Figure 3 Finite element model of screw-foams/bone. 
Table 1 Material properties of Ti alloy screw and Foams used in the current simulation

\begin{tabular}{|c|c|c|c|c|c|}
\hline Material properties & Density $\left(\mathrm{g} / \mathrm{cm}^{3}\right)$ & $\mathbf{v}$ & $\mathrm{E}(\mathrm{MPa})$ & $\sigma$ y $(\mathrm{MPa})$ & Reference \\
\hline Ti alloy screw & 4430 & 0.3 & 110000 & 860 & Chatzitergos et al. [16] \\
\hline Foam LD & 0.16 & 0.2 & 57 & 2.2 & Chapman et al. [23] \\
\hline Foam HD & 0.32 & 0.2 & 267 & 5.9 & Chapman et al. [23] \\
\hline
\end{tabular}

experimental data obtained from the current test and from Hashemi et al.'s study [22]. By applying similar boundary and loading conditions for the FE screw-foam model as in the experiment test, as shown in Figure 4. The global XYZ coordinate system was set with the $y$-axis acting along the axis of the screw length, and the $x$ - and $z$-axes pointing radially. The nodes in the circumferential surfaces of the foam were fixed in all degrees of freedom. The degrees of freedom in $x$ - and $z$ - direction translation were restricted, and a constant velocity of $0.01 \mathrm{~mm} / \mathrm{s}$, with displacement of $2.7 \mathrm{~mm}$ along the positive $y$-direction translation was prescribed to the pedicle screw [22].

The maximum reaction force, defined as $\mathrm{F}_{\mathrm{Q}}$, was extracted from all of the fully restrained nodes in the circumferential surfaces during the screw pullout procedure. The pullout force for a complete screw-foam model with $\mathrm{N}$ threads inserted into the cancellous bone, defined as F, was calculated based on equation (1):

$$
F=4 \times F_{Q} \times N
$$

with $\mathrm{N}=13$ to correlate with those in the current experiment and in the studies by Hashemi et al. [22].

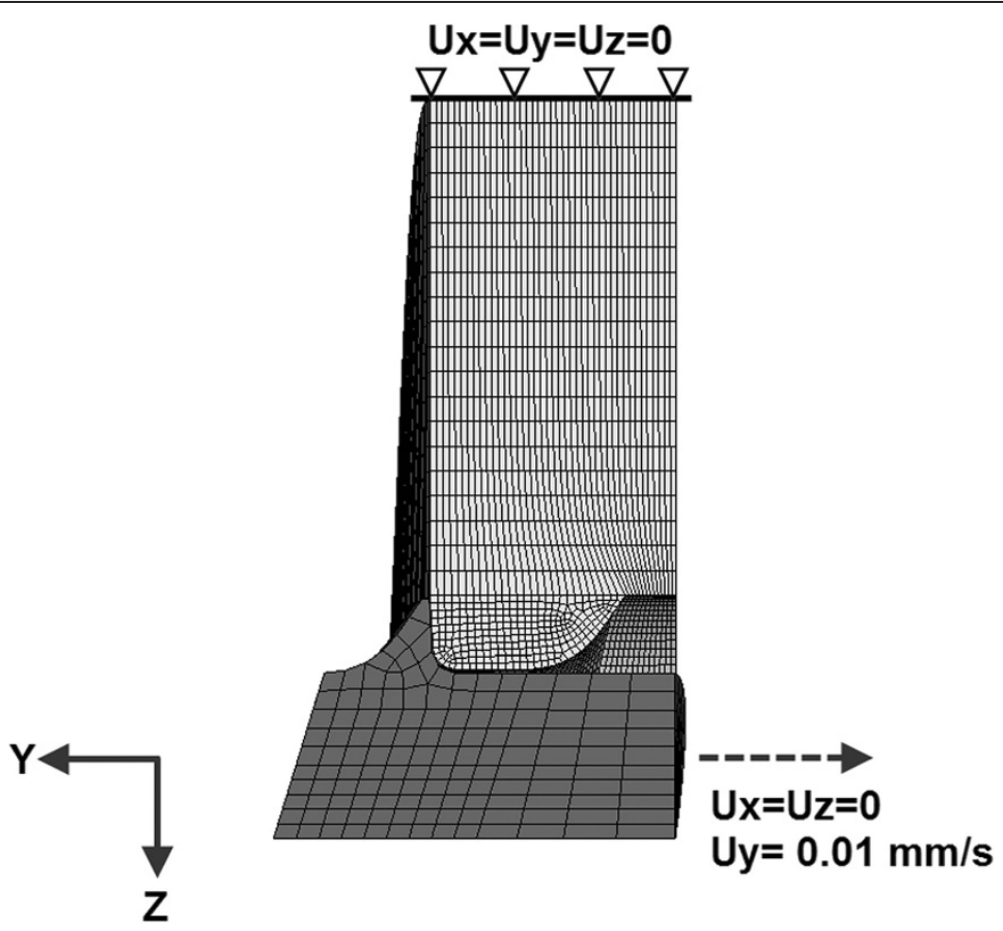

Figure 4 Boundary conditions and loading of the pullout simulation. 


\section{Calculation of RoE in cancellous bone: material sensitivity analysis}

For the material sensitivity study, the foam material properties of the validated screwfoam model were changed appropriately to emulate those of the cancellous bone. In this study, the cancellous bone was assumed to be homogeneous and, isotropic with an elastic-perfect plastic material, similar to those described in Hayes et al.'s study [26]. The material properties of cancellous bone, including its apparent density, Young's modulus and yield strength, as derived from the literature [20,21], were adopted. Young's modulus of cancellous bone ranged from $60 \mathrm{MPa}$ to $260 \mathrm{MPa}$ with an increment of $40 \mathrm{MPa}$ to simulate the 3 age groups $[27,28]$ in this study. A failure strain of $60 \%$ was assigned to the cancellous bone to define the failure behavior during the simulation [29]. The material properties of titanium alloy were used to model the screw. A friction coefficient of 0.2 was assigned for the contact surface between the screw and bone [30]. The material properties of all of the components described in the screwbone model are provided in Table 1 and Table 2. Similar boundary and loading conditions were applied to the screw-bone model to investigate the stress distribution in the bone tissue during pullout simulations in models with different material properties (Figure 4). During the simulation, the pullout forces and the stress distribution were documented along the radial path around the pedicle screw in cancellous bone.

During the screw pullout procedure, the reaction force at the screw head gradually increased to the maximum and then decreased, and the pullout force was defined as the maximum reaction force. The region of effect (RoE) was defined by the region surrounding the cancellous bone tissue with a von Mises stress value > $0.01 \mathrm{MPa}$ at the maximum reaction force. Then, based on the surrounding region, the RoE was estimated to be a circular area with a radius of $\Delta r$ beyond the outer pedicle screw radius, and the volume of the RoE for the complete screw, with a purchase length of $\mathrm{L}$, defined as $V_{A}$, was calculated from equation (2):

$$
V_{A}=\left[\pi(r+\Delta r)^{2}-\pi r^{2}\right] \times L
$$

Where:

$r$ : Outer radius $(\mathrm{mm})$ of pedicle screw;

$\Delta r$ : Radius (mm) of RoE;

$L$ : The purchase depth $(\mathrm{mm})$ of pedicle screw into the cancellous bone of vertebral body

At maximum pullout force, the stress distribution and magnitude in the cancellous bone along $\Delta r$ beyond the outer perimeter pedicle screw was also documented.

Table 2 Material properties of human cancellous bone used in the current simulation

\begin{tabular}{cccccc}
\hline Age & Density $\left(\mathbf{g} / \mathbf{c m}^{\mathbf{3}}\right)$ & $\boldsymbol{v}$ & $\mathbf{E}(\mathbf{M P a})$ & $\boldsymbol{\sigma} \mathbf{y}(\mathbf{M P a})$ & Reference \\
\hline Age $>$ 75 yr & 0.06 & 0.2 & 60 & 0.615 & Morgan et al. [20] \\
& 0.08 & & 100 & 1.015 & \\
Age 50-75 yr & 0.10 & 0.2 & 140 & 1.415 & Hou et al. [21] \\
& 0.12 & & 180 & 1.815 & \\
Age $<50 \mathrm{yr}$ & 0.14 & 0.2 & 220 & 2.215 & \\
& 0.16 & & 260 & 2.615 & \\
\hline
\end{tabular}




\section{Results}

\section{Experimental study and FE model validation}

The comparisons between the current FE predicted and experimental screw pullout strengths and the load-displacement graphs against those obtained from Hashemi et al.'s study [22], are shown in Table 3 and Figure 5. All of the load-displacement graphs showed similar trends, with the same orders of magnitude in the loads and reaching maximum values for displacement in the region of 1.5 to $2 \mathrm{~mm}$. The experimental measured pullout forces for the $\mathrm{CDH} 6.5$ screws were 2,015 $\pm 95.7 \mathrm{~N}$ and $657 \pm$ 69.4 $\mathrm{N}$ in high-density foam and low-density foam, respectively. Correspondingly, the FE predicted pullout forces were 2,028.8 $\mathrm{N}$ and $607 \mathrm{~N}$, respectively.

The stress distribution around the pedicle screw and material sensitivity analysis

The predicted pullout forces from the FE screw-bone models of different bone material properties are shown in Table 4. The results showed increased pullout force with the Young's modulus (the stiffness) of the bone block. The pullout forces with the bone's Young's modulus range from 220 to $260 \mathrm{MPa}$ (simulating age groups $<50$ years old) were $702 \mathrm{~N}$ and $1040 \mathrm{~N}$, respectively. These values are 2 to 3 times greater than those in the simulated 75 years old $>$ age $>50$ years old group $(442 \mathrm{~N}$ and $520 \mathrm{~N}$ ) and are 3 to 4 times greater than those in the simulated group of age $>75$ years old $(221 \mathrm{~N}$ and $273 \mathrm{~N})$.

Figure 6 shows the stress distribution around the pedicle screw for all of the simulated FE screw-bone models, demonstrating that the magnitude of the von Mises stress distribution in cancellous bone decreased gradually with similar patterns in the radial direction for all of the simulated FE screw-bone models. The highest magnitude of stress in the cancellous bone tissue was found in the region nearest the pedicle screw and it decreased as the distance between the bone tissue and the screw increased.

The results show that there existed a hypothetical effective region with radius of RoE $(\Delta r)$ and volume of $\operatorname{RoE}(V A)$ for the stabilization of the pedicle screw in screw-bone fixation. Table 5 shows that the predicted $\Delta r$ and $V A$ in cancellous bone around the pedicle screws increased with the stiffness of the bone block. $\Delta r s$ was 4.73, 5.06 and $5.4 \mathrm{~mm}$ in the simulated age group $>75$ years old, 75 years old $>$ age $>50$ years old and age $<50$ years old, respectively. The corresponding VA was $6.67,7.35$ and $8.07 \mathrm{ml}$, respectively.

\section{Discussion}

In the current study, an experimentally validated FE screw-bone model was established for the pullout simulation study, and the region of effect was investigated for pedicle screw stabilization around the pedicle screw during a pullout procedure. The results

Table 3 Comparison of predicted screw pullout strength against those in current test and the published literature

\begin{tabular}{lccccc}
\hline & \multicolumn{2}{c}{ Validation against our test } & & \multicolumn{2}{c}{ Validation against the test in literature } \\
\cline { 2 - 3 } & $\begin{array}{c}\text { The current experiment } \\
(\mathbf{n}=\mathbf{8})\end{array}$ & Predicted value & & $\begin{array}{c}\text { Hashemi et al.'s } \\
\text { experiment }(\mathbf{n}>\mathbf{4})\end{array}$ & Predicted value \\
\hline High density & $2015 \pm 95.7 \mathrm{~N}$ & $2028.8 \mathrm{~N}$ & & $2132.5 \pm 119.3 \mathrm{~N}$ & $2028.8 \mathrm{~N}$ \\
Low density & $657 \pm 69.4 \mathrm{~N}$ & $607 \mathrm{~N}$ & & $688.2 \pm 91.4 \mathrm{~N}$ & $607 \mathrm{~N}$ \\
\hline
\end{tabular}




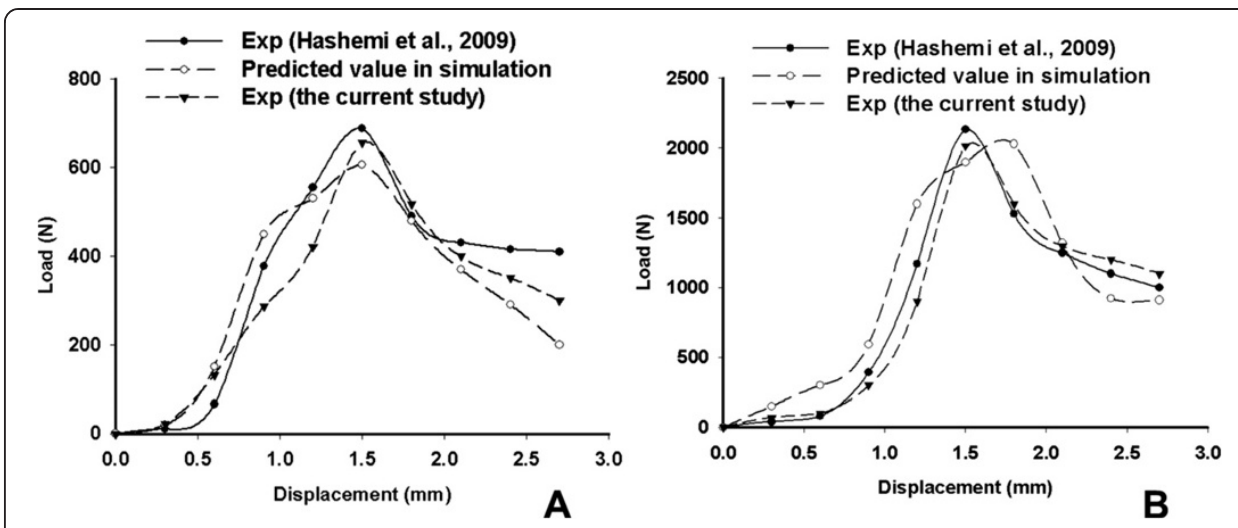

Figure $\mathbf{5}$ The load-displacement curve of pullout tests and simulation. A: in the lower density group; B: in the higher density group.

also showed that there existed a circular region in the cancellous bone around the pedicle screw, and this circular region was sensitive to the material properties of the cancellous bone.

The current study could provide spine surgeons with a clinical reference for pedicle screw instrumentation and augmentation. Many experimental studies have demonstrated that the stiffness and strength of pedicle screw-bone fixation could be significantly enhanced for screws augmented with various cements. Recently, several clinical studies have been conducted to investigate the application of cement augmentation for pedicle screw techniques [2,9,31]. However, cement has not been widely applied for pedicle screw augmentation clinically because of safety considerations. Moreover, a practical and reliable surgical technique for the augmentation of pedicle screws with cement has not yet been developed. Cement has many advantages for pedicle screw augmentation due to its high strength and rapid solidification, but an excessive volume of cement injection and posterior leakage of cement into the spinal canal can be catastrophic $[32,33]$. Based on the results of the current study, the augmentation of the hypothetical region of effect could improve the stability of pedicle screws, and an appropriate volume of cement injection could be established for clinical reference.

The FE screw-foam models, based on pedicle screw $\mathrm{CHH}$ 6.5, were developed for pullout simulations in the current study and were validated against the experimental pullout test conducted in Hashemi et al.'s study [22]. The screw pullout forces, extracted from two density screw-foam experimental tests and from simulated FE screwfoam models, showed direct proportionality to the strength of the material properties of the foam. The predicted pullout force and the load-displacement curves from the FE screw-foam models were of the same order of magnitude and showed similar trends with experimental results in Hashemi et al.'s study [22], as shown in Figure 5. These results demonstrated that FE screw-foam models were applicable for screw-bone pullout

Table 4 The pullout force (PF) in blocks with different material properties

\begin{tabular}{lcccccc}
\hline & \multicolumn{2}{c}{ Age $>\mathbf{7 5}$ yrs } & \multicolumn{7}{c}{$\mathbf{7 5}$ yrs $>$ age $>\mathbf{5 0}$ yrs } & \multicolumn{2}{c}{$\mathbf{5 0}$ yrs $>$ age } \\
\hline $\mathrm{E}(\mathrm{MPa})$ & 60 & 100 & 140 & 180 & 220 & $\mathbf{2 6 0}$ \\
$\mathrm{PF}(\mathrm{N})$ & 221 & 273 & 442 & 520 & 702 & 1040 \\
\hline
\end{tabular}




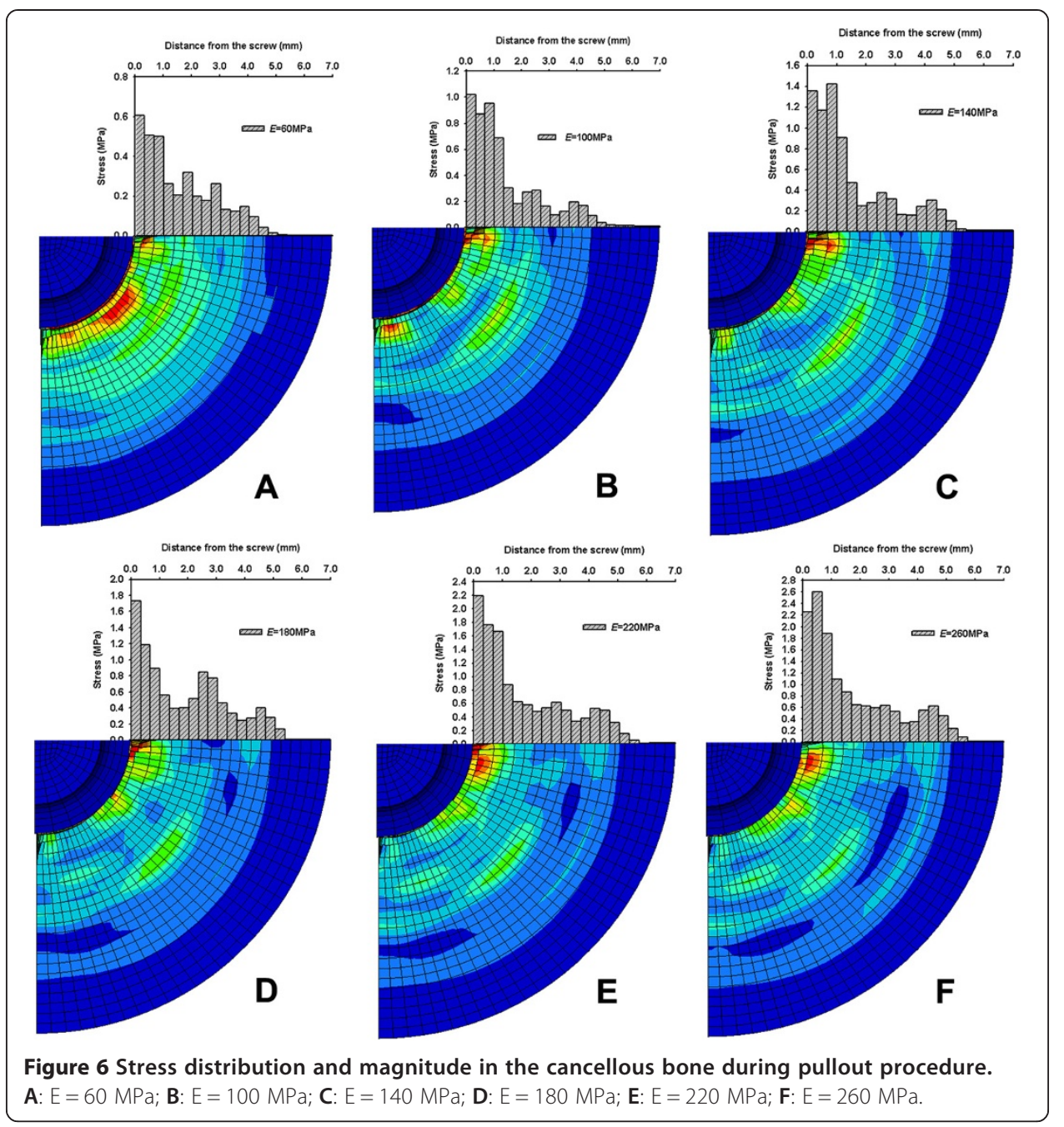

simulation, with appropriate material properties, allowing for the assumption of modeling the microstructure of cancellous bone as a cellular solid [34].

By changing the material of the mesh for the foam to that of cancellous bone, a modified FE screw-bone model was adopted for the pullout simulation to predict the pullout force and the hypothetical effective region (RoE) for screw stabilization. The FE computed results showed that the stress distribution pattern in cancellous bone around the pedicle screw was circular in shape. The stress magnitude was the highest in the region near the pedicle screw, and it decreased with the distance from the screw. This result supported the hypothesis that there existed a circular region around the pedicle screw, called the region of effect, which could play a pivotal role in screw stabilization.

As shown in the results, the range of RoE and screw pullout forces were affected by the mechanical properties of cancellous bone. However, Morgan et al. [20] and Hou

Table 5 The RoE in blocks around the pedicle screws with different material properties

\begin{tabular}{ccccccr}
\hline & \multicolumn{2}{c}{ Age $>\mathbf{7 5}$ yrs } & \multicolumn{2}{c}{$\mathbf{7 5}$ yrs $>$ age $>\mathbf{5 0}$ yrs } & \multicolumn{2}{c}{$\mathbf{5 0}$ yrs $>$ age } \\
\hline $\mathrm{E}(\mathrm{MPa})$ & 60 & 100 & 140 & 180 & 220 & 260 \\
$\Delta r(\mathrm{~mm})$ & 4.73 & 4.73 & 5.06 & 5.06 & 5.40 & 5.40 \\
$V A(\mathrm{ml})$ & 6.67 & 6.67 & 7.35 & 7.35 & 8.07 & 8.07 \\
\hline
\end{tabular}


et al. [21] reported that the material properties (density, stiffness, ultimate strength and yield strength) of cancellous bone changed with age. Therefore, with the different values of cancellous bone, Young's modulus (in various appropriate age groups) was used in the current study, and the corresponding predicted stress magnitudes in the cancellous bone showed that the RoE decreased with bone properties. The present study showed that $\Delta r$ ranged from 4.73 to $5.40 \mathrm{~mm}$ for standard 6.5 lumbar of specified thread profiles, and this range could vary depending on the screw type and thread profile (such as the thread shape factor and the inclination of the leading edge), which will be investigated in a further study.

In this study, the predicted RoE is based on the stress contour during the pullout simulation. The region with higher stress (near the pedicle screw) plays an important role in stabilizing the pedicle screw. The region with lower stress (distance away from the pedicle screw) carries less of a load in stabilizing the pedicle screw. We adopted the region with a von Mises stress value $<0.01 \mathrm{MPa}$ to be ineffective in the stabilization of the pedicle screw. Based on the material properties of the cancellous bone, with minimum yield stress of the cancellous bone in the age > 75 years old group of $0.615 \mathrm{MPa}$, and the value of $0.01 \mathrm{MPa}$ less than $2 \%$ of the yield stress, the region with von Mises stress value $<0.01 \mathrm{MPa}$ could therefore play a minor role in pedicle screw stabilization.

The development of any computational model requires a number of assumptions regarding the geometry, materials, and interactions between components. In the present study, the model was a quarter screw-foam/bone unit excluding the cortical bone. The commonly used standard of the $6.5 \mathrm{~mm}$ pedicle screw type in clinical application for fixation in osteoporotic patients was used in the modeling. Elastic-perfect plastic material properties were adopted for cancellous bone tissue in the current study, based on the Hayes et al.'s study [26], and these properties were sufficient for the relatively simple loading conditions for screw pullout. In the present simulation, $60 \%$ strain was used as the failure standard of the cancellous bone tissue [29]. Although the yield stress in cancellous bone occurs at strains of $5-10 \%$, the strain usually exceeds $60 \%$ before failure in the cellular structure of cancellous bone [26,35]. The friction coefficient between the screw and cancellous bone was set at 0.2 , based on previous studies [15,36]. In addition, a quarter screw-bone unit with fine mesh (mesh size: $0.1 \mathrm{~mm}$; elements number: $99,354)$ was established in the present study for computational efficiency. In the present study, the RoE was calculated without considering the material properties of the injection cement. Although the calculated RoE in the current simulation was a circular region around the outer radius of the pedicle screw, the RoE could change with the injection of various cements. We speculate that the properties of injection could influence the RoE, that cement with a higher Young's modulus, like PMMA, could enlarge the RoE in the cancellous bone, and that the RoE of biodegradable cement, such as $\mathrm{CPC}$ or hydroxyapatite, could vary with absorption of the biomaterials. Cancellous bone with various cement augmentations for pedicle screws requires further investigation.

\section{Conclusions}

In conclusion, the RoE was calculated based on an experimentally validated FE model in the present study. The results showed that there existed a circular region of effect around the pedicle screw during the pullout simulation. The RoE was sensitive to the 
material properties of the cancellous bone. The results suggested that the RoE could play a significantly role in pedicle screw augmentation, and the proper amount of injection cement for augmentation could be estimated in the treatment of osteoporosis patients for spine surgery.

Competing interests

The authors declare that they have no competing interests.

\title{
Authors' contributions
}

SL, WQ and YZ have made substantial contributions to conception and design, and acquisition of data, and analysis and interpretation of data; ZXW have been involved in drafting the manuscript and revising it critically for important intellectual content; YBY have given final approval of the version to be published; and WL agree to be accountable for all aspects of the work in ensuring that questions related to the accuracy or integrity of any part of the work are appropriately investigated and resolved. All authors read and approved the final manuscript.

\author{
Authors' information \\ SL: Department of Orthopaedics, Xijing Hospital, Fourth Military Medical University, Xi'an, China; \\ WQ: Surgery Department of 520 th Hospital of PLA, Mian yang, China; \\ YZ: Department of Orthopaedics, Xijing Hospital, Fourth Military Medical University, Xi'an, China; \\ ZXW: Department of Orthopaedics, Xijing Hospital, Fourth Military Medical University, Xi'an, China; \\ YBY: Department of Orthopaedics, Xijing Hospital, Fourth Military Medical University, Xi'an, China; \\ WL: Department of Orthopaedics, Xijing Hospital, Fourth Military Medical University, Xi'an, China. \\ Shuai Liu, Wei Qi and Yang Zhang are the co-first authors.
}

\section{Acknowledgements}

The authors acknowledge the Chinese Scholarship Council (CSC) for the financial support on the international exchange.

\section{Author details}

'Department of Orthopaedics, Xijing Hospital, Fourth Military Medical University, Xi'an 710032, Shaanxi Province, P.R. China. ${ }^{2}$ Surgery Department of 520 th Hospital of PLA, Mian yang, China.

Received: 9 February 2014 Accepted: 17 June 2014

Published: 21 June 2014

\section{References}

1. Allen RT, Lee YP, Garfin SR: Spine surgeons survey on attitudes regarding osteoporosis and osteomalacia screening and treatment for fractures, fusion surgery, and pseudoarthrosis. Spine J 2009, 9(7):602-604.

2. Kim KH, Lee SH, Lee DY, Shim CS, Maeng DH: Anterior bone cement augmentation in anterior lumbar interbody fusion and percutaneous pedicle screw fixation in patients with osteoporosis. J Neurosurg Spine 2010, 12(5):525-532.

3. Chen CS, Chen WJ, Cheng CK, Jao SH, Chueh SC, Wang CC: Failure analysis of broken pedicle screws on spinal instrumentation. Med Eng Phys 2005, 27(6):487-496.

4. Halvorson TL, Kelley LA, Thomas KA, Whitecloud TS 3rd, Cook SD: Effects of bone mineral density on pedicle screw fixation. Spine (Phila Pa 1976) 1994, 19(21):2415-2420.

5. Hasegawa K, Takahashi HE, Uchiyama S, Hirano T, Hara T, Washio T, Sugiura T, Youkaichiya M, Ikeda M: An experimental study of a combination method using a pedicle screw and laminar hook for the osteoporotic spine. Spine (Phila Pa 1976) 1997, 22(9):958-962. discussion 963.

6. Liu D, Lei W, Wu ZX, Gao MX, Wan SY, Fu SC, Shi L: Augmentation of pedicle screw stability with calcium sulfate cement in osteoporotic sheep: biomechanical and screw-bone interfacial evaluation. J Spinal Disord Tech 2011, 24(4):235-241.

7. Liu D, Wu ZX, Gao MX, Wan SY, Shi L, Fu SC, Wang J, Lei W: A new method of partial screw augmentation in sheep vertebrae in vitro: biomechanical and interfacial evaluation. J Spinal Disord Tech 2011, 24(5):318-324.

8. Wuisman PI, Van Dijk M, Staal H, Van Royen BJ: Augmentation of (pedicle) screws with calcium apatite cement in patients with severe progressive osteoporotic spinal deformities: an innovative technique. Eur Spine J 2000, 9(6):528-533.

9. Chang MC, Liu CL, Chen TH: Polymethylmethacrylate augmentation of pedicle screw for osteoporotic spinal surgery: a novel technique. Spine (Phila Pa 1976) 2008, 33(10):E317-E324.

10. Burval DJ, McLain RF, Milks R, Inceoglu S: Primary pedicle screw augmentation in osteoporotic lumbar vertebrae: biomechanical analysis of pedicle fixation strength. Spine (Phila Pa 1976) 2007, 32(10):1077-1083.

11. Linhardt O, Luring C, Matussek J, Hamberger C, Plitz W, Grifka J: Stability of pedicle screws after kyphoplasty augmentation: an experimental study to compare transpedicular screw fixation in soft and cured kyphoplasty cement. J Spinal Disord Tech 2006, 19(2):87-91.

12. Yilmaz C, Atalay B, Caner H, Altinors N: Augmentation of a loosened sacral pedicle screw with percutaneous polymethylmethacrylate injection. J Spinal Disord Tech 2006, 19(5):373-375.

13. MacLeod AR, Pankaj P, Simpson A: Does screw-bone interface modelling matter in finite element analyses? J Biomech 2012, 45(9):1712-1716.

14. Moazen M, Mak JH, Jones AC, Jin Z, Wilcox RK, Tsiridis E: Evaluation of a new approach for modelling the screw-bone interface in a locking plate fixation: A corroboration study. Proc Inst Mech Eng H 2013, 227(7):746-756. 
15. Zhang QH, Tan SH, Chou SM: Effects of bone materials on the screw pull-out strength in human spine. Med Eng Phys 2006, 28(8):795-801.

16. Chatzistergos PE, Magnissalis EA, Kourkoulis SK: A parametric study of cylindrical pedicle screw design implications on the pullout performance using an experimentally validated finite-element model. Med Eng Phys 2010, 32(2):145-154.

17. Gao M, Lei W, Wu Z, Liu D, Shi L: Biomechanical evaluation of fixation strength of conventional and expansive pedicle screws with or without calcium based cement augmentation. Clin Biomech (Bristol, Avon) 2011, 26(3):238-244

18. Wu ZX, Lei W, Hu YY, Wang HQ, Wan SY, Ma ZS, Sang HX, Fu SC, Han YS: Effect of ovariectomy on BMD, micro-architecture and biomechanics of cortical and cancellous bones in a sheep model. Med Eng Phys 2008, 30(9):1112-1118.

19. Yan YB, Qi W, Wang J, Liu LF, Teo EC, Tianxia Q, Ba JJ, Lei W: Relationship between architectural parameters and sample volume of human cancellous bone in micro-CT scanning. Med Eng Phys 2011, 33(6):764-769.

20. Morgan EF, Bayraktar HH, Keaveny TM: Trabecular bone modulus-density relationships depend on anatomic site. J Biomech 2003, 36(7):897-904.

21. Hou FJ, Lang SM, Hoshaw SJ, Reimann DA, Fyhrie DP: Human vertebral body apparent and hard tissue stiffness. J Biomech 1998, 31(11):1009-1015.

22. Hashemi A, Bednar D, Ziada S: Pullout strength of pedicle screws augmented with particulate calcium phosphate: an experimental study. Spine J 2009, 9(5):404-410.

23. Chapman JR, Harrington RM, Lee KM, Anderson PA, Tencer AF, Kowalski D: Factors affecting the pullout strength of cancellous bone screws. J Biomech Eng 1996, 118(3):391-398.

24. Grewal AS, Sabbaghian M: Load distribution between threads in threaded connections. J Press Vess-T Asme 1997, 119(1):91-95.

25. Macdonald KA, Deans WF: Stress-analysis of drillstring threaded connections using the finite-element method. Eng Fail Anal 1995, 2(1):1-30.

26. Hayes WC, Carter DR: Postyield behavior of subchondral trabecular bone. J Biomed Mater Res 1976, 10(4):537-544.

27. Kopperdahl DL, Keaveny TM: Yield strain behavior of trabecular bone. J Biomech 1998, 31(7):601-608.

28. McDonald K, Little J, Pearcy M, Adam C: Development of a multi-scale finite element model of the osteoporotic lumbar vertebral body for the investigation of apparent level vertebra mechanics and micro-level trabecular mechanics. Med Eng Phys 2010, 32(6):653-661.

29. Mercer C, He MY, Wang R, Evans AG: Mechanisms governing the inelastic deformation of cortical bone and application to trabecular bone. Acta Biomater 2006, 2(1):59-68.

30. Liu CL, Chen HH, Cheng CK, Kao HC, Lo WH: Biomechanical evaluation of a new anterior spinal implant. Clin Biomech (Bristol, Avon) 1998, 13(1 Suppl 1):S40-S45.

31. Wu ZX, Gao MX, Sang HX, Ma ZS, Cui G, Zhang Y, Lei W: Surgical treatment of osteoporotic thoracolumbar compressive fractures with open vertebral cement augmentation of expandable pedicle screw fixation: a biomechanical study and a 2-year follow-up of 20 patients. J Surg Res 2012, 173(1):91-98.

32. Jung MY, Shin DA, Hahn IB, Kim TG, Huh R, Chung SS: Serious complication of cement augmentation for damaged pilot hole. Yonsei Med J 2010, 51(3):466-468.

33. Golz T, Graham CR, Busch LC, Wulf J, Winder RJ: Temperature elevation during simulated polymethylmethacrylate (PMMA) cranioplasty in a cadaver model. J Clin Neurosci 2010, 17(5):617-622.

34. Gibson L: Biomechanics of cellular solids. J Biomech 2005, 38(3):377-399.

35. Bayraktar HH, Morgan EF, Niebur GL, Morris GE, Wong EK, Keaveny TM: Comparison of the elastic and yield properties of human femoral trabecular and cortical bone tissue. J Biomech 2004, 37(1):27-35.

36. Zhang QH, Tan SH, Chou SM: Investigation of fixation screw pull-out strength on human spine. J Biomech 2004, 37(4):479-485.

doi:10.1186/1475-925X-13-83

Cite this article as: Liu et al: Effect of bone material properties on effective region in screw-bone model: an experimental and finite element study. BioMedical Engineering OnLine 2014 13:83.

\section{Submit your next manuscript to BioMed Central and take full advantage of:}

- Convenient online submission

- Thorough peer review

- No space constraints or color figure charges

- Immediate publication on acceptance

- Inclusion in PubMed, CAS, Scopus and Google Scholar

- Research which is freely available for redistribution 